\title{
19. A List of Chromosome Numbers in Angiospermous Plants IX.
}

\author{
By Toranosuke Sugiura.
}

Botanical Institute, Osaka Higher School.

(Comm. by K. FuJII, M.I.A., Feb. 12, 1943.)

In the following table the meiotic numbers of chromosomes in 33 plants belonging to 9 families recently examined, are enumerated.

The more detailed chromosomic descriptions with illustrations will be published later.

The division of the pollen mother cells in all plants here listed is carried out by the furrowing method (cf. Sugiura, 1936)*).

\begin{tabular}{|c|c|c|c|}
\hline Plants investigated & $\begin{array}{c}\text { Chromo- } \\
\text { some } \\
\text { number } \\
\text { (ln) }\end{array}$ & Plants investigated & $\begin{array}{c}\text { Chromo- } \\
\text { some } \\
\text { number } \\
(\ln )\end{array}$ \\
\hline Asteraceae & & Scabiosa integrifolia & 10 \\
\hline Centaurium ramosissimum & 24 & S. $\quad$ lucida & 8 \\
\hline Campanulaceae & & maritima & 8 \\
\hline Campanula eriocalyx & 34 & ochroleuca & 8 \\
\hline C. Kolenatiana & 17 & orientalis & 8 \\
\hline Komarovi & 17 & semipapposa & 8 \\
\hline Leutweinii & 17 & S. $\quad$ ucranica & 8 \\
\hline C. $\quad$ peregrina & 51 & Succisa pratensis & 9 \\
\hline Michauxia campanuloides & 17 & S. $\quad$ suaveolens & 8 \\
\hline Dipsacaceae & 1 & Gesneriaceae & \\
\hline Cephalaria corniculata & 9 & Streptocarpus tubiflora & 16 \\
\hline C. $\quad$ gracea & 9 & Scrophulariaceae & \\
\hline leucantha & 9 & Linaria genistifolia & 9 \\
\hline C. $\quad$ radiata & 9 & Cistaceae & \\
\hline Scabiosa amoena & 8 & Cistus incanus & 9 \\
\hline S. $\quad$ arenaria & 8 & Melianthaceae & \\
\hline atropurpurea & 8 & Melianthus comosa & 18 \\
\hline canescens & 8 & Papaveraceae & \\
\hline caucasica & 8 & Coreanomecon hylomeconoides & 6 \\
\hline Fischeri & 8 & Alizoaceae & \\
\hline graminifolia & 8 & Glottiphyllum praepinque & 18 \\
\hline
\end{tabular}

*) Sugiura, T. $1936 \mathrm{~b}$. Studies on the chromosome numbers in higher plants, with special reference to cytokinesis, I. Cytologia, 7. 